\title{
Longitudinal Effects of Ketamine on Dendritic Architecture In Vivo in the Mouse Medial Frontal Cortex ${ }^{1,2,3}$
}

\author{
Victoria Phoumthipphavong, ${ }^{1}$ Florent Barthas, ${ }^{1}$ Samantha Hassett, ${ }^{1}$ and ${ }^{1}$ Alex C. Kwan ${ }^{1,2}$
}

DOI:http://dx.doi.org/10.1523/ENEURO.0133-15.2016

${ }^{1}$ Department of Psychiatry, Yale University, New Haven, Connecticut 06511, and ${ }^{2}$ Department of Neuroscience, Yale University, New Haven, Connecticut 06511

\begin{abstract}
A single subanesthetic dose of ketamine, an NMDA receptor antagonist, leads to fast-acting antidepressant effects. In rodent models, systemic ketamine is associated with higher dendritic spine density in the prefrontal cortex, reflecting structural remodeling that may underlie the behavioral changes. However, turnover of dendritic spines is a dynamic process in vivo, and the longitudinal effects of ketamine on structural plasticity remain unclear. The purpose of the current study is to use subcellular resolution optical imaging to determine the time course of dendritic alterations in vivo following systemic ketamine administration in mice. We used two-photon microscopy to visualize repeatedly the same set of dendritic branches in the mouse medial frontal cortex (MFC) before and after a single injection of ketamine or saline. Compared to controls, ketamine-injected mice had higher dendritic spine density in MFC for up to 2 weeks. This prolonged increase in spine density was driven by an elevated spine formation rate, and not by changes in the spine elimination rate. A fraction of the new spines following ketamine injection was persistent, which is indicative of functional synapses. In a few cases, we also observed retraction of distal apical tuft branches on the day immediately after ketamine administration. These results indicate that following systemic ketamine administration, certain dendritic inputs in MFC are removed immediately, while others are added gradually. These dynamic structural modifications are consistent with a model of ketamine action in which the net effect is a rebalancing of synaptic inputs received by frontal cortical neurons.
\end{abstract}

Key words: dendrites; dendritic spines; frontal cortex; ketamine; structural plasticity; two-photon microscopy

\section{Significance Statement}

A single dose of ketamine leads to fast-acting antidepressant effects, and thus understanding its mechanism of action would facilitate the development of new treatments for mood disorders. One potential mechanism is the remodeling of synaptic connections, because ketamine administration in rodents leads to a higher density of dendritic spines in the frontal cortex. Structural remodeling, however, is a dynamic process, and the longitudinal effects of ketamine are poorly understood. In this study, we used subcellular resolution optical imaging methods to repeatedly visualize dendritic spines from the same set of neurons for $>2$ weeks in the mouse frontal cortex. The results are consistent with a model of action for ketamine involving the rebalancing of synaptic inputs in the frontal cortex. 


\section{Introduction}

Major depressive disorder is a top contributor to disease burden among mental illnesses in the United States (Murray et al., 2013). Core symptoms for depressive disorders are debilitating, yet treatment options are limited. Typical antidepressants require several weeks to months to be effective, and approximately one-third of patients remain nonresponsive even after multiple trials. In contrast to the slow onset of action for the currently available antidepressants, a single dose of ketamine produces antidepressant effects within several hours (Berman et al., 2000) and can last for up to 2 weeks (lbrahim et al., 2012). Studies of ketamine effects in animal models have found antidepressant-like behavioral responses in naive and stressed rodents (Li et al., 2010; Autry et al., 2011; Li et al., 2011; Donahue et al., 2014). These studies have shed light on the molecular signaling pathways recruited by systemic ketamine administration. However, still unclear are the cellular and network mechanisms responsible for the behavioral improvements (Sanacora and Schatzberg, 2015).

One striking consequence of systemic ketamine administration in naive rodents is an increase in the dendritic spine density in the distal and proximal tufts of layer 5 pyramidal neurons in the medial prefrontal cortex (Li et al., 2010; Liu et al., 2013; Ruddy et al., 2015). These observations of synaptogenesis are in stark contrast with the structural and synaptic atrophy reported for patients with major depression (Drevets et al., 1997; Kang et al., 2012) and in chronic stress models (Cook and Wellman, 2004; Radley et al., 2004; Liston et al., 2006; Christoffel et al., 2011). The opposing effects of ketamine and stress on neural architecture suggest that there could be a structural basis for antidepressant actions. Namely, fast-acting antidepressants such as ketamine may restore synaptic connections that were lost in stress and mood disorders (Duman and Aghajanian, 2012). Indeed, when chronically stressed rats were injected with a single dose of ketamine, the stress-induced reduction in dendritic spine density could be reversed (Li et al., 2011).

However, the turnover of dendritic spines is a dynamic process in vivo. An increase in dendritic spine density could be due to an increase in formation rate, a decrease

Received November 6, 2015; accepted March 15, 2016; First published March 23, 2016.

${ }^{1}$ The authors declare no competing financial interests.

${ }^{2}$ Author Contributions: V.P. and A.C.K. designed research; V.P. and F.B. performed research; V.P., S.H., and A.C.K. analyzed data; V.P. and A.C.K. wrote the paper.

${ }^{3}$ This work was supported by a NARSAD Young Investigator Award (A.C.K.), and the Golden Rule Family Foundation (A.C.K.).

Acknowledgments. We thank Ronald Duman and George Aghajanian for helpful discussions, William Cafferty for providing mice for pilot experiments, and Jaime Grutzendler for mice and advice on the surgery.

Correspondence should be addressed to Alex C. Kwan, Department of Psychiatry, Yale University, 300 George Street, Suite 901, New Haven, CT 06511. E-mail: alex.kwan@yale.edu.

DOI:http://dx.doi.org/10.1523/ENEURO.0133-15.2016

Copyright (C) 2016 Phoumthipphavong et al.

This is an open-access article distributed under the terms of the Creative Commons Attribution 4.0 International, which permits unrestricted use, distribution and reproduction in any medium provided that the original work is properly attributed. in elimination rate, or a combination of both factors. Moreover, newly formed spines can be transient or persistent, either disappearing or stabilizing after several days. It is unknown whether new spines following systemic ketamine are persistent and thus are associated with functional synapses (Knott et al., 2006). Characterizing these dynamics requires longitudinal methods. Two-photon microscopy is an optical imaging technique that enables the visualization of dendritic architecture in vivo at subcellular resolution for up to several months (Grutzendler et al., 2002; Holtmaat et al., 2009). This approach has been used to investigate structural plasticity following sensory experience (Trachtenberg et al., 2002), learning (Fu et al., 2012; Lai et al., 2013), and exposure to substances, including corticosterone (Liston and Gan, 2011) and cocaine (Muñoz-Cuevas et al., 2013).

In this study, we used two-photon imaging to characterize the effects of a single subanesthetic dose of ketamine on the dendritic architecture in the mouse medial frontal cortex (MFC). Our results showed that systemic ketamine leads to a relative increase in dendritic spine density, a prolonged change driven by an elevated rate of spine formation. A fraction of the ketamine-induced new spines was persistent and could be observed after $4 \mathrm{~d}$, which is indicative of functional synapses. Unexpectedly, we also observed a loss of distal apical tuft branches that occurred specifically and immediately on the day after ketamine administration. These data demonstrate distinct short- and long-term consequences of ketamine on dendritic architecture, and highlight its impact on modifying the synaptic inputs impinging on frontal cortical neurons.

\section{Materials and Methods}

\section{Mice}

All animal procedures were performed in accordance with the regulations of the Yale University animal care committee. Experiments were performed on adult (postnatal day 73-149) Thy1-GFP-M ( $n=13$; \#007788, The Jackson Laboratory, RRID:IMSR_JAX:007788) and Thy1YFP- $H$ transgenic mice $(n=3$; \#003782, The Jackson Laboratory, RRID:IMSR_JAX:003782). Mice of both sexes were used. Mice were housed under controlled temperature on a $12 \mathrm{~h}$ light/dark cycle with siblings (one to five per cage) and nesting material.

\section{Surgery}

Anesthesia was induced with a $2 \%$ isoflurane and oxygen mixture, which was lowered to $1.5 \%$ for the remainder of the surgery. Mice were secured by ear bars in a stereotaxic frame. Their body temperature was regulated with a hot water circulation pad. Mice were injected with carprofen (5 mg/kg, s.c.; catalog \#024751, Butler Schein Animal Health) and dexamethasone $(40 \mathrm{mg} / \mathrm{kg}$, i.m.; catalog \#D4902, Sigma-Aldrich) prior to surgery. A 2- to 3-mm-diameter craniotomy was made over the right medial frontal cortex (AP = $1.5 \mathrm{~mm}, \mathrm{ML}=0.5 \mathrm{~mm}$ ) with a handheld dental drill. After the skull was carefully removed, the surface of the brain was irrigated with an artificial cerebrospinal fluid (ACSF; in mM: 5 $\mathrm{KCl}, 5 \mathrm{HEPES}, 135 \mathrm{NaCl}, 1 \mathrm{MgCl}$, and $1.8 \mathrm{CaCl}$, $\mathrm{pH} 7.3)$ until bleeding subsides. A drop of warmed, low-melting 
point agarose solution (2\% in ACSF; Type III-A, High EEO agarose, catalog \#A9793, Sigma-Aldrich) was applied over the craniotomy. A two-layer glass plug was fabricated by first etching out a 2-mm-diameter circle from a \#0 thickness glass coverslip, then bonded with UV-activated epoxy (NT37-322, Edmund Optics) to a \#1 thickness, 3-mmdiameter round glass coverslip (catalog \#64-0720-CS-3R, Warner Instruments). The glass plug was placed over the craniotomy and held in place until the agarose solidifies. The glass plug was then stabilized by applying light pressure and adding superglue around the edges. A stainless steel head plate was affixed to the skull using C\&B-METABOND (Parkell Inc.). Mice were given another dose of carprofen (5 $\mathrm{mg} / \mathrm{kg}$, s.c.) immediately after surgery and for each of the following $3 \mathrm{~d}(5 \mathrm{mg} / \mathrm{kg}$, i.p.). Mice were given a period of at least 3 weeks to recover before imaging begins.

\section{Imaging}

Mice were anesthetized with 1.5\% isoflurane and head fixed. Temperature was regulated using a heating pad with rectal probe feedback. The two-photon microscope (Movable Objective Microscope, Sutter Instrument) was controlled using the Scanlmage software (Pologruto et al., 2003, RRID:SCR_014307). Excitation was provided by an ultrafast laser (Chameleon Ultra II, Coherent) and focused with a high-numerical aperture microscope objective (XLUMPLFLN20X/1.0, Olympus). For imaging green fluorescent protein (GFP)- or yellow fluorescent protein (YFP)expressing dendrites, excitation wavelength was set at 920 $\mathrm{nm}$, and emission was collected behind a bandpass filter from 475 to $550 \mathrm{~nm}$. Each mouse was injected with either ketamine (10 mg/kg, i.p.) or saline vehicle on a non-imaging day. To investigate short-term effects, mice were imaged on days $-3,-1$, and 1 relative to the day of injection. For long-term studies, mice were imaged on days $-3,-1,1,3$, 5,10 , and 15 relative to the day of injection. Multiple fields of view were imaged in the same mouse. The same field of view was identified across days by finding landmark structures such as blood vessels or an edge of the glass window. At each field of view, image stacks were acquired at $1024 \times$ 1024 pixels, spanning a field of view of $60.5 \times 60.5 \mu \mathrm{m}$, and at $2 \mu \mathrm{m}$ steps for a $z$-range of $20-30 \mu \mathrm{m}$. Each imaging session lasted up to $2.5 \mathrm{~h}$. Although we did not explicitly record the duration of imaging sessions, we estimated post hoc based on the acquisition times of the first and last image files in the computer.

\section{Image analysis}

In all of the figures, we are presenting the raw images with only adjustments to the black-and-white levels (linear), with no modification to contrast (nonlinear) or removal of neighboring axons, or any other manipulations. Initially, image stacks were processed for motion correction using the StackReg plug-in (Thévenaz et al., 1998, RRID:SCR_014308) in ImageJ (Schneider et al., 2012, RRID:SCR_003070). Then, structural parameters were analyzed from each image stack using ImageJ. The physical parameters of dendritic spines were characterized based on criteria established in a standardized protocol (Holtmaat et al., 2009). Briefly, dendritic spines were counted if the protrusions extended at least $0.4 \mu \mathrm{m}$ away from the shaft.
Dendritic spine length was the distance from the base at the shaft to the tip. Dendritic spine head diameter was the width at the widest extent of the spine. Distances were measured using the line segment tool in ImageJ. The dendritic spine formation rate was defined as the number of new spine protrusions observed in two consecutive imaging sessions divided by the total number of dendritic spines in the first imaging session. To assess longitudinal changes in the spine formation rate, we calculated the difference from baseline by subtracting the formation rate of each field of view by the baseline rate of the subject. The baseline rate of each subject was estimated by averaging the spine formation rates of all fields of view imaged from the same individual prior to injection (i.e. between days -3 and -1 ). The dendritic elimination rate was quantified using the same procedure for spine protrusions that disappeared. Most of the sessions were imaged $2 \mathrm{~d}$ apart, but some sessions were imaged $5 \mathrm{~d}$ apart (i.e., days 5-10 and days 10-15). Presumably, with the same spine formation rate, we would observe more new spines in sessions occurring $5 \mathrm{~d}$ apart relative to those occurring $2 \mathrm{~d}$ apart because more time has elapsed. Therefore, when estimating the spine formation/ elimination rate from new/lost spine counts, we report turnover rates for sessions occurring $5 \mathrm{~d}$ apart with a correction factor, by multiplying the measured rates by two-fifths. For the apical tuft branches, dendritic segments were traced over using the freehand line tool, and then summed for total length in ImageJ. To assess longitudinal changes of the imaged dendritic segments, we calculated the fold change from the last session for each field of view by dividing the measured branch length of an imaging session by that of the prior imaging session.

\section{Statistics}

We performed statistical tests considering fields of view as independent samples. This is a major assumption, justified in part by the fact that the fields of view were at random, nonoverlapping locations and that each one comprises a very small portion $(0.06 \%)$ of the window area of each mouse. The reason for making this assumption is that a different number of fields of view was obtained for each mouse, so if we compare subjects only, the results will have a bias for those with fewer fields of view. To ensure that this assumption does not affect the major conclusions of the study, we repeated statistical tests in data from three sessions considering each mouse as a sample when possible. For all longitudinal results, two-way mixed ANOVA with repeated measures was used to test the factors contributing to changes in spine density, dendritic branch length, spine formation rate, and spine elimination rate. The factors were treatment (with ketamine or saline; between-subject), day (within-subject), and their interaction. The two-tailed $t$ test was used to compare means that did not involve multiple days. The two-sample Kolmogorov-Smirnov test was used to compare cumulative distributions. Data are reported as the mean \pm SEM. Table 1 contains a list of the statistical tests performed, $p$ values, and sample sizes. $p$ values and sample sizes are reported instead of observed power to provide more information on the samples involved and be- 
Table 1: Statistical table

\begin{tabular}{|c|c|c|c|c|c|}
\hline a & Spine density & $\begin{array}{l}\text { Data structure } \\
\text { Two-factor, btw (treatment) and win (day) }\end{array}$ & $\begin{array}{l}\text { Test } \\
\text { rANOVA }\end{array}$ & $\begin{array}{l}\text { Exact } p \text { value } \\
\text { Treatment: } p=6 \times 10^{-7} \text {; day: } p=0.40 \text {; } \\
\quad \text { interaction: } p=0.39\end{array}$ & $\begin{array}{l}N \\
28 / 25 \text { fields of view for } 7 \\
\quad \text { sessions for ket vs saline }\end{array}$ \\
\hline$b$ & Spine formation rate & Two-factor, btw (treatment) and win (day) & rANOVA & $\begin{array}{l}\text { Treatment: } p=0.03 ; \text { day: } p=0.001 \\
\quad \text { interaction: } p=0.03\end{array}$ & $\begin{array}{l}\text { 58/97 fields of view for } 3 \\
\text { sessions for ket vs saline }\end{array}$ \\
\hline c & Spine elimination rate & Two-factor, btw (treatment) and win (day) & rANOVA & $\begin{array}{l}\text { Treatment: } p=0.9 ; \text { day: } p=0.003 \\
\quad \text { interaction: } p=0.9\end{array}$ & $\begin{array}{l}58 / 97 \text { fields of view for } 3 \\
\text { sessions for ket vs saline }\end{array}$ \\
\hline$d$ & Spine formation rate & Two-factor, btw (treatment) and win (day) & rANOVA & $\begin{array}{l}\text { Treatment: } p=2 \times 10^{-4} \text {; day: } \\
\quad p=0.5 ; \text { interaction: } p=0.08\end{array}$ & $\begin{array}{l}28 / 25 \text { fields of view for } 7 \\
\text { sessions for ket vs saline }\end{array}$ \\
\hline e & Spine elimination rate & Two-factor, btw (treatment) and win (day) & rANOVA & $\begin{array}{l}\text { Treatment: } p=0.1 ; \text { day: } p=0.001 \\
\quad \text { interaction: } p=0.07\end{array}$ & $\begin{array}{l}28 / 25 \text { fields of view for } 7 \text { sessions } \\
\text { for ket vs saline }\end{array}$ \\
\hline$f$ & Field of view fraction & Normally distributed & $\chi^{2}$ test & $p=0.005$ & $\begin{array}{l}58 / 97 \text { fields of view } \\
\text { for ket vs saline }\end{array}$ \\
\hline $\mathrm{g}$ & Spine density & Two-factor, btw (treatment) and win (day) & rANOVA & $\begin{array}{l}\text { Treatment: } p=0.007 ; \text { day: } p=0.87 \\
\quad \text { interaction: } p=0.98\end{array}$ & $8 / 8$ mice for ket vs saline \\
\hline $\mathrm{h}$ & Spine formation rate & Two-factor, btw (treatment) and win (day) & rANOVA & $\begin{array}{l}\text { Treatment: } p=0.07 ; \text { day: } p=0.20 \\
\quad \text { interaction: } p=0.69\end{array}$ & $8 / 8$ mice for ket vs saline \\
\hline $\mathrm{i}$ & Spine elimination rate & Two-factor, btw (treatment) and win (day) & rANOVA & $\begin{array}{l}\text { Treatment: } p=0.64 ; \text { day: } p=0.23 \\
\quad \text { interaction: } p=0.62\end{array}$ & $8 / 8$ mice for ket vs saline \\
\hline j & Persistent fraction & Normally distributed & Two-tailed $t$ test & $p=0.3$ & $\begin{array}{l}28 / 25 \text { fields of view for } \\
\text { ket vs saline }\end{array}$ \\
\hline $\mathrm{k}$ & Persistent fraction & Normally distributed & Two-tailed paired $t$ test & $p=0.007$ & 28 fields of view for ket \\
\hline $\mathrm{m}$ & Persistent fraction & Normally distributed & Two-tailed paired $t$ test & $p=0.002$ & 28 fields of view for ket \\
\hline $\mathrm{n}$ & Persistent fraction & Normally distributed & Two-tailed paired $t$ test & $p=0.1$ & 25 fields of view for saline \\
\hline o & Persistent fraction & Normally distributed & Two-tailed paired $t$ test & $p=0.9$ & 25 fields of view for saline \\
\hline $\mathrm{p}$ & Spine head length & Normally distributed & Two-tailed paired $t$ test & $p=0.02$ & $328 / 328$ new vs existing spines \\
\hline$q$ & Spine head width & Normally distributed & Two-tailed paired $t$ test & $p=3 \times 10^{-5}$ & $328 / 328$ new vs existing spines \\
\hline$r$ & Spine head length & Cumulative fractions & $\begin{array}{l}\text { Two-sample Kolmogorov- } \\
\text { Smirnov test }\end{array}$ & $p=9 \times 10^{-6}$ & $328 / 328$ new vs existing spines \\
\hline s & Spine head width & Cumulative fractions & $\begin{array}{l}\text { Two-sample Kolmogorov- } \\
\text { Smirnov test }\end{array}$ & $p=4 \times 10^{-4}$ & $328 / 328$ new vs existing spines \\
\hline $\mathrm{t}$ & Spine head length & Cumulative fractions & $\begin{array}{l}\text { Two-sample Kolmogorov- } \\
\text { Smirnov test }\end{array}$ & $p=0.9$ & $\begin{array}{l}61 / 328 \text { spines for pre-ket } \\
\text { vs post-ket }\end{array}$ \\
\hline $\mathrm{u}$ & Spine head length & Cumulative fractions & $\begin{array}{l}\text { Two-sample Kolmogorov- } \\
\text { Smirnov test }\end{array}$ & $p=0.09$ & $\begin{array}{l}61 / 328 \text { spines for pre-ket } \\
\text { vs post-ket }\end{array}$ \\
\hline$v$ & Spine head width & Cumulative fractions & $\begin{array}{l}\text { Two-sample Kolmogorov- } \\
\text { Smirnov test }\end{array}$ & $p=0.2$ & $\begin{array}{l}61 / 328 \text { spines for pre-ket } \\
\text { vs post-ket }\end{array}$ \\
\hline w & Spine head width & Cumulative fractions & $\begin{array}{l}\text { Two-sample Kolmogorov- } \\
\text { Smirnov test }\end{array}$ & $p=0.5$ & $\begin{array}{l}61 / 328 \text { spines for pre-ket } \\
\text { vs post-ket }\end{array}$ \\
\hline$x$ & Dendrite length & $\begin{array}{l}\text { Two-factor, btw (treatment) } \\
\text { and win (day) }\end{array}$ & rANOVA & $\begin{array}{l}\text { Treatment: } p=1 \times 10^{-12} ; \text { day: } \\
\quad p=0.02 ; \text { interaction: } p=0.02\end{array}$ & $\begin{array}{l}28 / 25 \text { fields of view for } 7 \\
\text { sessions for ket vs saline }\end{array}$ \\
\hline $\mathrm{y}$ & $\begin{array}{l}\text { Dendrite length and } \\
\text { formation rate }\end{array}$ & $\begin{array}{l}\text { Two variables: binary (with or without branch } \\
\text { loss) and continuous (formation rate) }\end{array}$ & Regression coefficient & $p=0.2$ & 28 fields of view for ket \\
\hline z & $\begin{array}{l}\text { Dendrite length and } \\
\text { elimination rate }\end{array}$ & $\begin{array}{l}\text { Two variables: binary (with or without branch } \\
\text { loss) and continuous (elimination rate) }\end{array}$ & Regression coefficient & $p=0.3$ & 28 fields of view for ket \\
\hline aa & $\begin{array}{l}\text { Branch width of imaged } \\
\text { dendritic segments }\end{array}$ & Normally distributed & Two-tailed $t$ test & $p=0.44$ & $\begin{array}{l}117 \text { stable and } 16 \text { retracted } \\
\text { dendritic segments }\end{array}$ \\
\hline$a b$ & Dendrite length & $\begin{array}{l}\text { Two-factor, btw (treatment) } \\
\text { and win (day) }\end{array}$ & rANOVA & $\begin{array}{l}\text { Treatment: } p=0.003 \text {; day: } p=0.69 \\
\quad \text { interaction: } p=0.69\end{array}$ & $8 / 8$ mice for ket vs saline \\
\hline ac & $\begin{array}{l}\text { Change in dendritic } \\
\text { spine density }\end{array}$ & Non-parametric & Wilcoxon ranked-sum & $p=1$ & $8 / 8$ mice for ket vs saline \\
\hline ad & $\begin{array}{l}\text { Change in dendritic } \\
\text { spine density }\end{array}$ & Non-parametric & Wilcoxon ranked-sum & $p=0.3$ & 5 female and 11 male mice \\
\hline $\mathrm{ae}$ & $\begin{array}{l}\text { Change in dendritic } \\
\text { spine density }\end{array}$ & Two continuous variables & Regression coefficient & $p=0.8$ & 16 mice \\
\hline af & $\begin{array}{l}\text { Change in dendritic } \\
\text { spine density }\end{array}$ & Two continuous variables & Regression coefficient & $p=0.8$ & 16 mice \\
\hline ag & $\begin{array}{l}\text { Change in dendritic } \\
\text { spine density }\end{array}$ & Two continuous variables & Regression coefficient & $p=0.16$ & 16 mice \\
\hline
\end{tabular}

rANOVA, repeated measures ANOVA; btw, between-factor of the ANOVA; win, within-factor of the ANOVA; ket, ketamine administration; saline, saline administration.

cause the $p$ values are directly related to the observed power.

\section{Results}

\section{Longitudinal imaging of dendritic architecture in the mouse medial frontal cortex in vivo}

To visualize dendritic architecture, we performed twophoton microscopy (Fig. 1A,B) using the transgenic Thy1GFP-M and Thy1-YFP-H mice (Feng et al., 2000), in which a sparse subset of neocortical neurons expresses the enhanced GFP or YFP. Many studies have used these mouse lines to investigate structural remodeling, but primarily in the sensory cortices (Trachtenberg et al., 2002; Knott et al., 2006). Therefore, we started by examining the distribution of fluorescent neurons in the frontal cortex. Fluorescence imaging of fixed coronal sections confirmed sparse labeling in anterior cingulate cortex (Cg1) and secondary motor cortex (M2; Fig. 1C). In these regions, fluorescence signals originated predominantly from layer 5 pyramidal neurons, as is evident from the laminar posi- 
A

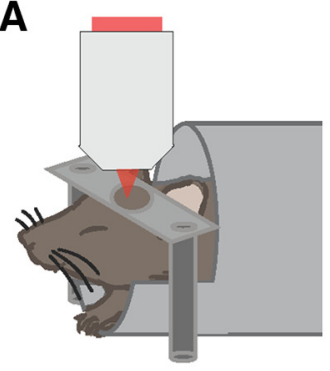

D

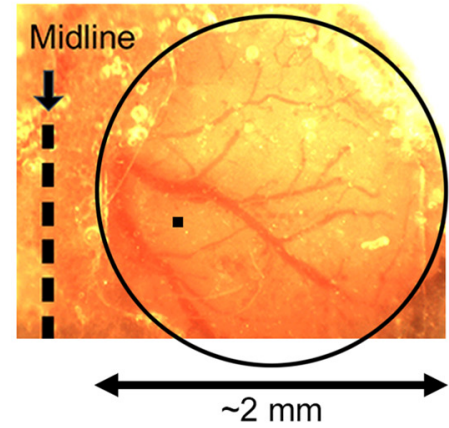

B

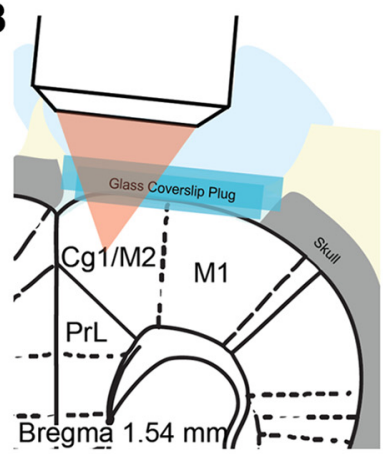

C

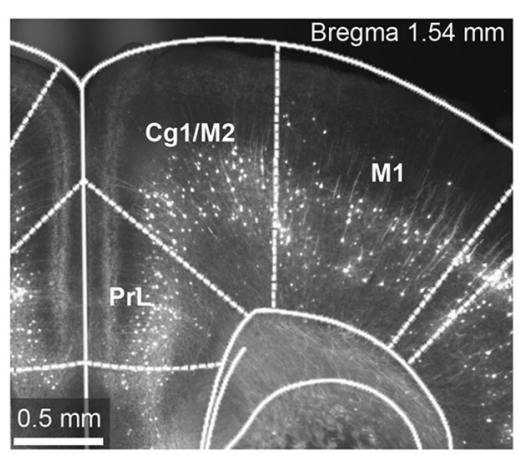

E

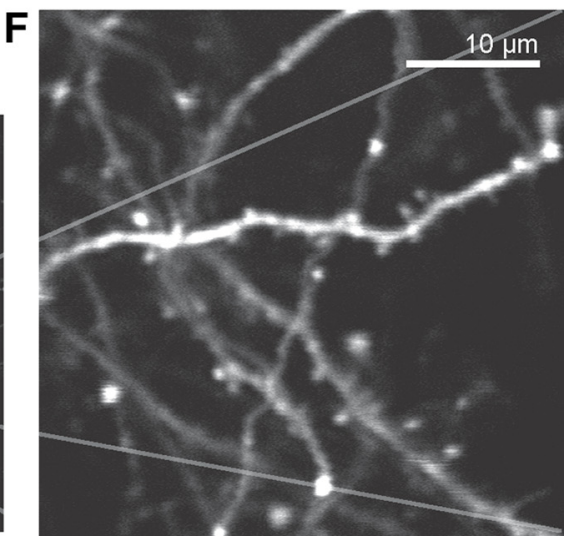

Figure 1. Longitudinal imaging of dendritic architecture in the mouse medial frontal cortex. $\boldsymbol{A}$, Schematic of the imaging experiment. $\boldsymbol{B}$, Schematic of the long-term window implant. $\boldsymbol{C}$, Fluorescence image of a fixed coronal brain slice from a Thy $1-G F P-M$ mouse following longitudinal imaging. $\mathrm{Cg} 1$ and M2 (i.e., the MFC) were imaged in this study. PrL, prelimbic cortex. M1, primary motor cortex. $\boldsymbol{D}$, Bright-field image of the long-term window implant. The glass window has an $\sim 2-\mathrm{mm}$-diameter width (circle), which is much larger than the imaging field of view of $\sim 60 \times 60 \mu \mathrm{m}$ (filled square). $\boldsymbol{E}, \mathrm{A}$ low-magnification, in vivo two-photon image from layer 1 of the MFC in a Thy1-GFP-M mouse. Distal apical tuft branches from GFP-expressing layer 5 pyramidal neurons were visible. $\boldsymbol{F}$, A high-magnification image of a region in $\boldsymbol{E}$.

tion of the cell bodies. This is consistent with the knowledge that only deep-layer pyramidal neurons are labeled in these two mouse lines (Feng et al., 2000). Interestingly, although there were no fluorescent cell bodies in the superficial layers, a band of the fluorescence signal could be seen in layer $2 / 3$, particularly in the medial regions. This band may arise from axons in other brain regions, such as basolateral amygdala, that send long-range projections to frontal cortical regions (Oh et al., 2014).

In this study, we imaged layer 1 of the MFC, which includes $\mathrm{Cg} 1$ and M2. The choice of MFC was due to practical reasons because two-photon microscopy has depth limitations. Nevertheless, MFC is appropriate for studies of antidepressants as numerous studies have reported stress-induced structural and functional alterations in rodents, either specifically in the cingulate region (Liston et al., 2006; Ito et al., 2010; Kassem et al., 2013) or in a greater region that includes MFC (Radley et al., 2004; 2006; Cerqueira et al., 2007). These results are consistent with a recent brain-wide mapping study, which identified both $\mathrm{Cg} 1$ and $\mathrm{M} 2$ as regions with significantly reduced activity levels in a learned helplessness model of depression (Kim et al., 2016). Moreover, mapping of metabolic activity after systemic ketamine showed that MFC is among the activated brain regions in rodents (Duncan et al., 1999; Miyamoto et al., 2000). To prepare for longitudinal in vivo imaging, we performed a craniotomy above MFC and implanted a long-term 2-mm-diameter glass window (Fig. 1D). After recovery, mice were anesthetized with isoflurane and affixed on head posts under a two-photon microscope. Figure $1 E$ shows a low-magnification image of the GFP-expressing dendrites in MFC in vivo. For counting dendritic spines, we acquired high-magnification 20- to 30- $\mu \mathrm{m}$ thick image stacks at multiple fields of view (Fig. 1F). Individual dendritic branches could be distinguished from axons by the protruding dendritic spines along the segments. Because we were imaging superficial layers, these neuronal processes represented the distal apical tuft branches of layer 5 pyramidal neurons. We note that all images presented in this article have only linear adjustments to black-and-white levels, but have not otherwise been altered (see Materials and Methods).

\section{Systemic ketamine administration is associated with higher dendritic spine density in MFC for 2 weeks}

To examine the effects of ketamine on structural plasticity in the MFC, we visualized the same fields of view on multiple imaging sessions in adult mice, while administering either a single subanesthetic dose of ketamine (10 
A Ketamine or saline
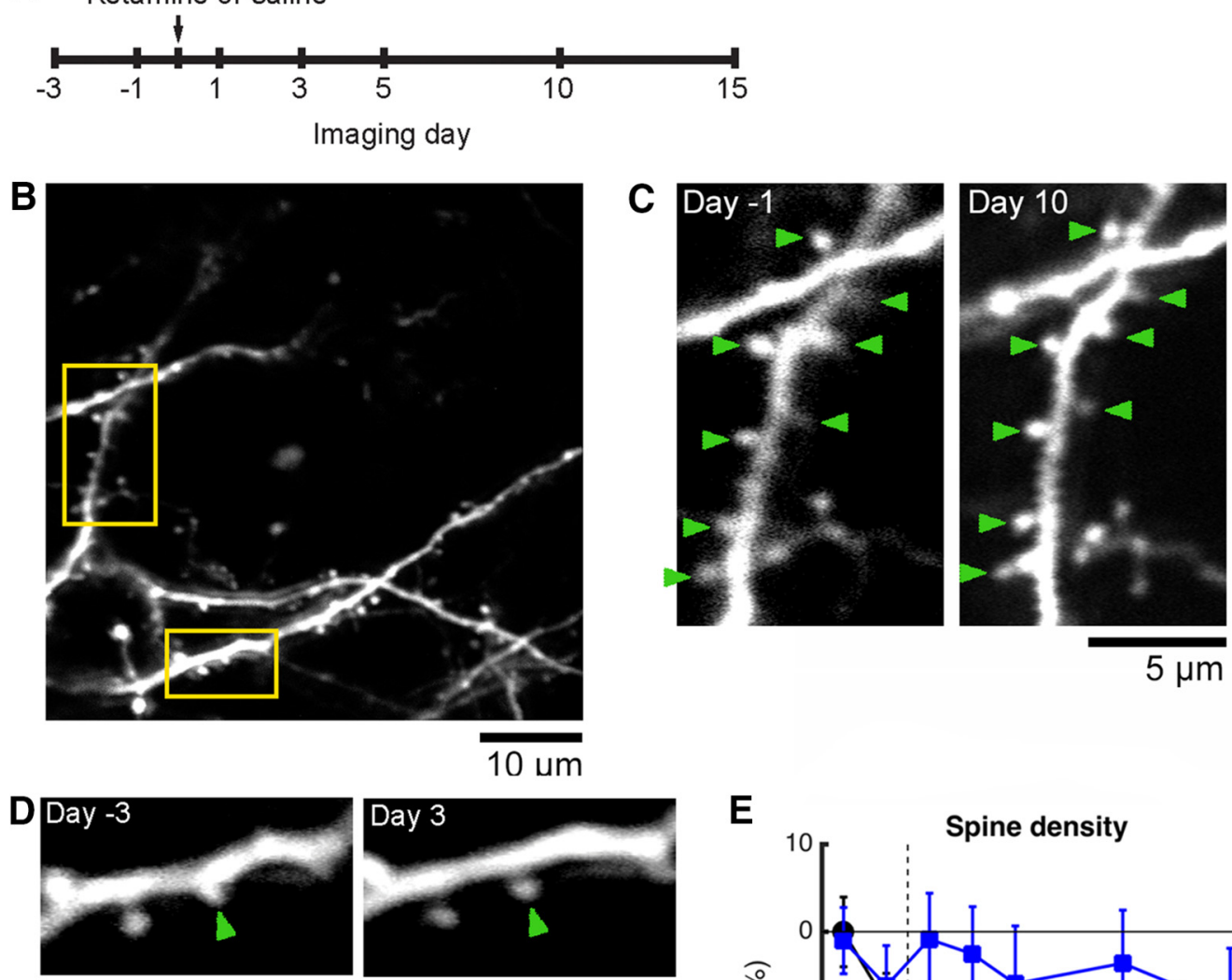

E
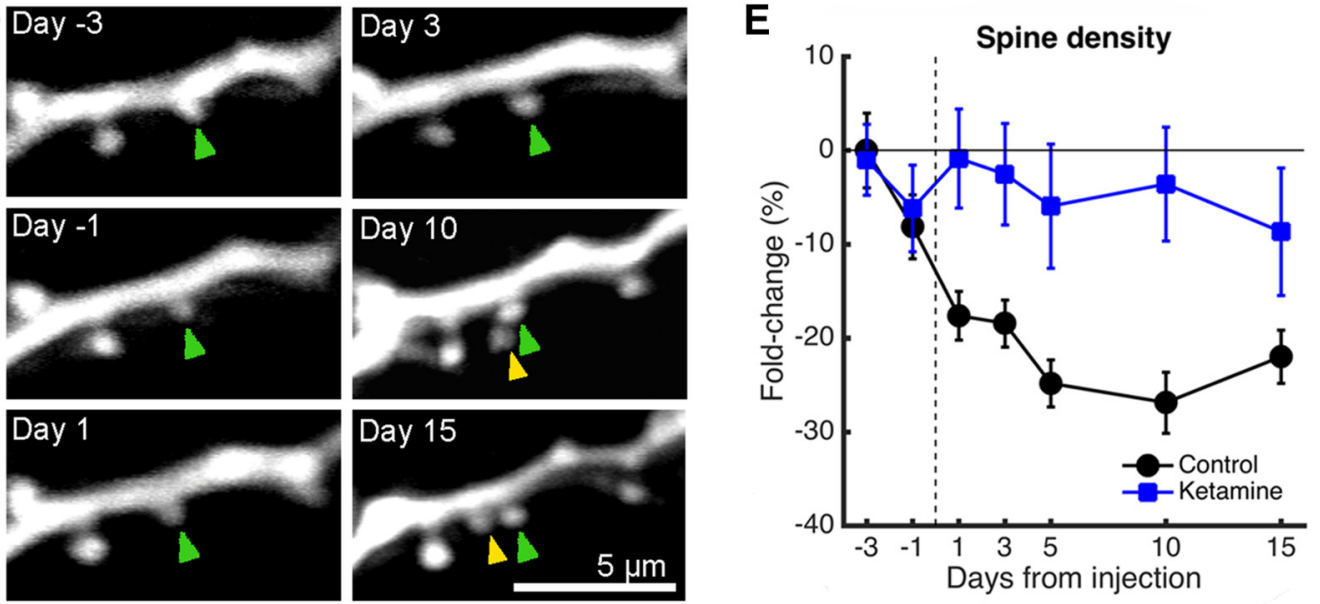

Figure 2. Systemic ketamine administration leads to higher dendritic spine density for at least 2 weeks relative to that of controls. $\boldsymbol{A}$, Time line of the experiment. Ketamine was administered at a dose of $10 \mathrm{mg} / \mathrm{kg}$ through intraperitoneal injection. $\boldsymbol{B}$, An example imaging field of view acquired on day -3 in a Thy1-GFP-M mouse. Yellow boxes indicate the dendritic branches shown as examples in $\boldsymbol{C}$ and $\boldsymbol{D}$. $\boldsymbol{C}$, Images of an apical dendritic tuft branch at days -1 and 10 from ketamine administration in a Thy1-GFP-M mouse. In the bottom right, axonal processes and boutons are visible. Green arrowhead, stable spine. $\boldsymbol{D}$, Another apical dendritic tuft branch from the same field of view at days $-3,-1,1,3,10$, and 15 from ketamine administration in a Thy1-GFP-M mouse. A new spine (yellow arrowhead) appeared on day 10 next to a stable spine (green arrowhead). $\boldsymbol{E}$, Change in dendritic spine density across days, expressed as a fold change from the value measured on the first imaging session. The mouse was injected with either ketamine (blue square) or saline (black circle). Values are reported as the mean \pm SEM. $N=28$ and 25 fields of view across 7 sessions for ketamineand saline-injected mice.

$\mathrm{mg} / \mathrm{kg}$, i.p.) or saline vehicle (Fig. $2 A)$. We imaged on days $-3,-1,1,3,5,10$, and 15 from the injection day. We did not image on the injection day because anesthesia would interfere with neural activity, which is required for the antidepressant effects of ketamine (Fuchikami et al., 2015). We focused on the medial half of the 2-mmdiameter glass window. Image stacks were acquired from multiple, nonoverlapping fields of view $(60.5 \times 60.5 \mu \mathrm{m})$, each representing a tiny portion of the window area (0.06\%; Fig. 1D). In total, we tracked 1,665 spines for ketamine ( $n=8$ mice; 58 fields of view, range 4-21 per mouse) and 3,814 spines for saline ( $n=8$ mice; 97 fields of view, range 4-17 per mouse). All the experiments involved at least the first three sessions. In a subset of experiments, we tracked dendritic architecture for the full seven-session period, including 800 spines for ketamine $(n=3$ mice; 28 fields of view) and 783 spines for saline ( $n$ = 2 mice; 25 fields of view). For each field of view, we counted multiple branches including dozens of dendritic spines $($ mean $=38$ spines/field of view, SD $=17$ ). In the 
first imaging session, we measured the mean baseline dendritic spine density in MFC to be 0.28 spines/ $\mu \mathrm{m}$ (SD $=0.08 ; n=155$ fields of view). This value for dendritic spine density is $\sim 25 \%$ lower than a previous measurement from the mouse dorsomedial prefrontal cortex (Muñoz-Cuevas et al., 2013), a difference that may be attributed to our mice being older adults.

Comparing the pre-ketamine administration and postketamine administration sessions, most dendritic spines were stable (Fig. 2C,D, green arrowheads). However, there were also instances where new spines were found (Fig. 2D, yellow arrowhead). To summarize data for ketamine and saline conditions, we quantified the fold change in dendritic spine density from baseline (day -3 from injection) for each field of view. Systemic ketamine was associated with higher dendritic spine density in the MFC (treatment: $p=6 \times 10^{-7}, F_{(1,276)}=26.0$; day: $p=$ $0.40, F_{(5,276)}=1.03$; interaction: $p=0.39, F_{(5,276)}=1.05$; two-way ANOVA; Fig. $2 E$ ) relative to the saline group. It is noteworthy that we also observed a decline in dendritic spine density across days for saline-injected subjects (Fig. 2E, black line). This reduction of spine density in the "control" condition may be due to a number of factors, which will be discussed in a later section.

\section{Higher dendritic spine density is driven by an elevated rate of spine formation}

Next we wanted to find the changes in dendritic spine turnover dynamics responsible for the relative increase in dendritic spine density. Because the largest spine density increase was found on the day after ketamine injection, we focused the analysis on the entire dataset across a period including days $-3,1$, and 1 (Fig. $3 A$ ). Figure $3 B$ shows two image montages of apical tuft branches before and after ketamine injection. To quantify spine turnover dynamics, we compared the same fields of view across consecutive imaging sessions to count the number of new and eliminated spines. Relative to the preinjection baseline, we found an increase in spine formation rate following systemic ketamine injection that was different from that found in the saline group (treatment: $p=0.03, F_{(1,287)}$ $=4.61$; day: $p=0.001, F_{(1,287)}=10.3$; interaction: $p=$ $0.03, F_{(1,287)}=4.61$; two-way ANOVA; Fig. $\left.3 C\right)$. In contrast, although there were changes in spine elimination rates across days, there was no difference between mice that received ketamine or saline (treatment: $p=0.9$, $F_{(1,286)}=0.02$; day: $p=0.003, F_{(1,286)}=9.09$; interaction: $p=0.9, F_{(1,286)}=0.02$; two-way ANOVA; Fig. $\left.3 D\right)$. We also plotted the spine turnover rates using only the sevensession dataset for the ketamine (Fig. $3 E$ ) and saline groups (Fig. 3F). Ketamine remained a significant factor contributing to a difference in spine formation rate (treatment: $p=2 \times 10^{-4}, F_{(1,267)}=14.5$; day: $p=0.5, F_{(5,267)}$ $=0.89$; interaction: $p=0.08, F_{(5,267)}=1.96$; two-way ANOVA), but not in the spine elimination rate (treatment: $p$ $=0.1, F_{(1,267)}=2.79$; day: $p=0.001, F_{(5,267)}=4.19$; interaction: $p=0.07, F_{(5,267)}=2.03$; two-way ANOVA). These results indicate that an elevated rate of spine formation is the driving force behind the higher spine density in the MFC following ketamine administration.
Although the mean spine formation rate was higher for mice with systemic ketamine administration relative to saline administration, there was variability across fields of view (Fig. 3G). As described previously, there was a decline in spine density across days in saline-injected subjects, and accordingly $83 \%$ of the imaged field of dendritic tuft branches had reduced spine density compared with the first-day baseline. By contrast, about half of the fields of view had an increase in spine density following ketamine injection (40\%; $p=0.005, \chi^{2}=7.8, \chi^{2}$ test). Using fields of view allows us to examine more finely the variability in the data; however, the results could be correlated among fields of view from the same individual. Therefore, we verified, on a per-subject basis across $7 \mathrm{~d}$, that there is a significant effect of treatment on dendritic spine density (treatment: $p=0.007, F_{(1,16)}=9.39$; day: $p$ $=0.87, F_{(5,16)}=0.35$; interaction: $p=0.46, F_{(5,16)}=0.98$; two-way ANOVA), that there is an effect that was near to but did not reach statistical significance for the effect of treatment on spine formation rate (treatment: $p=0.07$, $F_{(1,16)}=3.87$; day: $p=0.96, F_{(5,16)}=0.20$; interaction: $p$ $=0.69, F_{(5,16)}=0.62$; two-way ANOVA), and that there is no effect of treatment on spine elimination rate (treatment: $p=0.64, F_{(1,16)}=0.23$; day: $p=0.23, F_{(5,16)}=1.56$; interaction: $p=0.62, F_{(5,16)}=0.71$; two-way ANOVA).

\section{A fraction of the newly formed spines associated with ketamine administration is persistent}

An important question is whether the new dendritic spines associated with ketamine administration become functional synapses. A previous study (Knott et al., 2006) correlated images from two-photon and electron microscopy to show that a fraction of the newly formed dendritic spines is transient and disappears, whereas persistent spines that are stable for $>4 \mathrm{~d}$ had synapses. For the new spines that were observed on the day following ketamine or saline injection, we quantified the fraction that could be observed at the same location $4 \mathrm{~d}$ later. Across fields of view, we found no difference in the fraction of spines that became persistent for ketamine versus that for saline (mean \pm SEM: ketamine, $39 \pm 5 \%$; saline, $32 \pm$ $4 \% ; p=0.3, t_{(40)}=0.99$, unpaired $t$ test; Fig. $\left.4 A\right)$. However, the persistent fraction decreased over longer periods for ketamine-injected mice (day 5 vs day 10: $p=$ $0.007, t_{(17)}=3.08$; day 5 vs day $15: p=0.002, t_{(15)}=3.85$; paired $t$ test, exact $p$ values were reported without multiple-comparison adjustment), whereas it was unchanged for saline-injected mice (day 5 vs day 10: $p=$ $0.1, t_{(19)}=1.74$; day 5 vs day $15: p=0.9, t_{(12)}=-0.17$; paired $t$ test, exact $p$ values were reported without multiple-comparison adjustment).

Furthermore, larger spines are known to correlate with more mature and stronger synaptic connections (Kasai et al., 2003). We measured the length and width of spine heads, comparing between newly formed spines, and matched each of those with a neighboring stable spine on the same dendritic branch. Relative to existing spines, new spines that appeared immediately on the day following systemic ketamine were shorter (mean \pm SEM: new, $1.25 \pm 0.04 \mu \mathrm{m}, n=328$; existing, $1.35 \pm 0.03 \mu \mathrm{m}, n=$ 
A

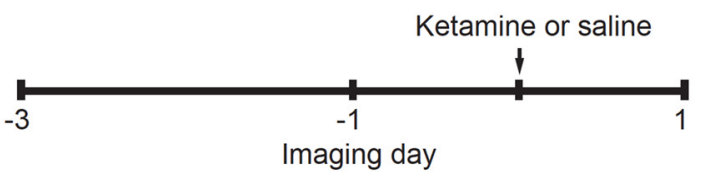

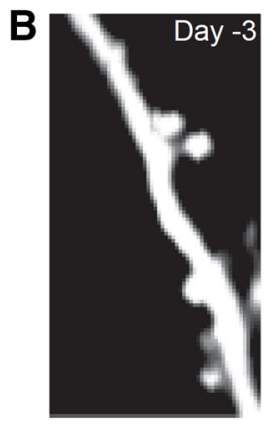
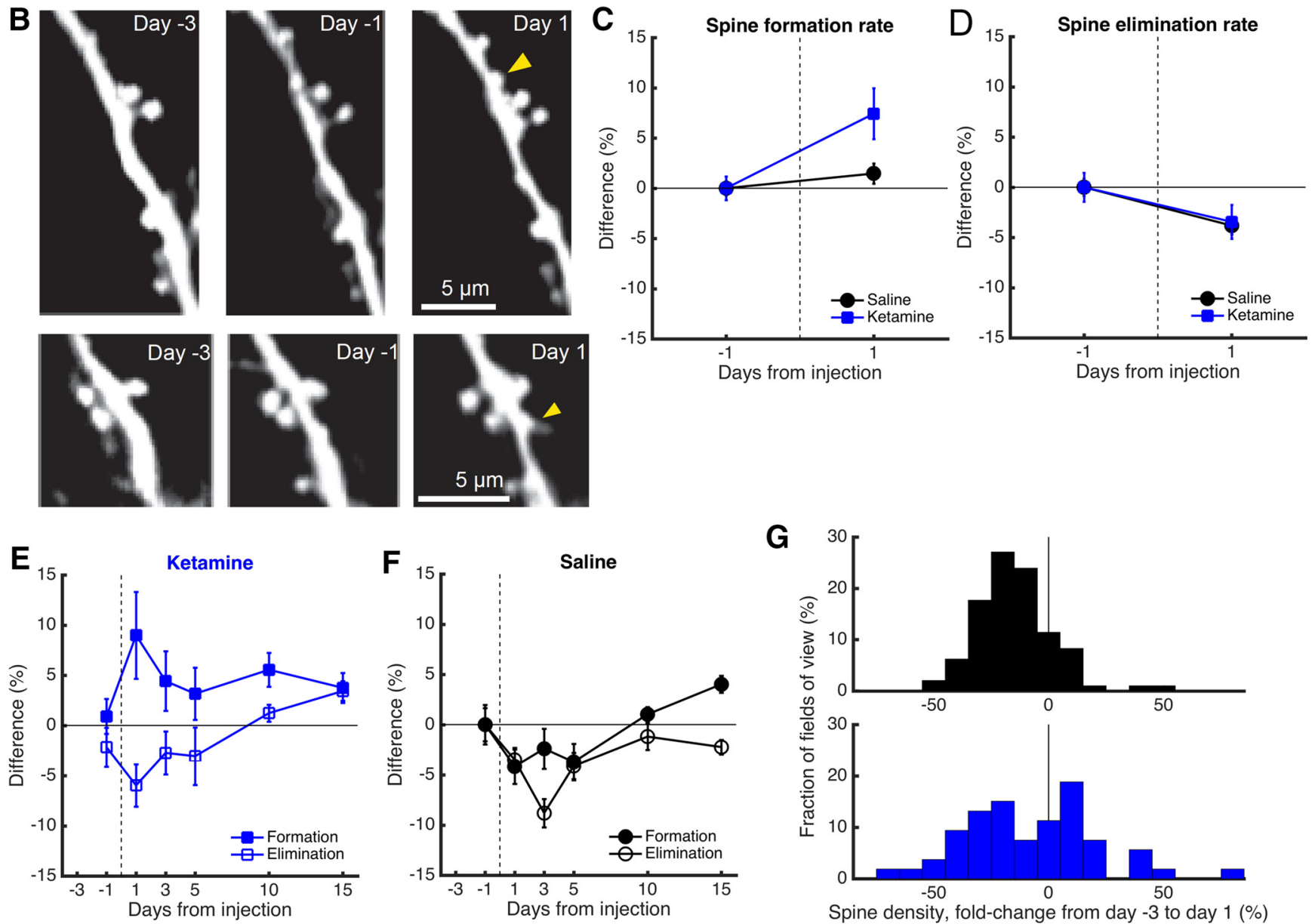

Spine density, fold-change from day -3 to day 1 (\%)

Figure 3. Higher spine density is due to an elevated rate of spine formation. $\boldsymbol{A}$, Time line of the experiment. Ketamine was administered at a dose of $10 \mathrm{mg} / \mathrm{kg}$ through intraperitoneal injection. $\boldsymbol{B}$, Images of two different apical dendritic tuft branches at days $-3,-1$, and 1 from ketamine administration in a Thy1-GFP-M mouse. Yellow arrowhead, new spine. $\boldsymbol{C}$, Change in spine formation rate, expressed as the difference from the value measured between days -3 and -1 (i.e., preinjection sessions). The mouse was injected with either ketamine (blue square) or saline (black circle). Values are reported as the mean \pm SEM. $N=58$ and 97 fields of view across three sessions for ketamine- and saline-injected mice. $\boldsymbol{D}$, Same as $\boldsymbol{C}$ for spine elimination rate. $\boldsymbol{E}$, Change in spine turnover dynamics across days for mice injected with ketamine. Solid square, spine formation rate. Open square, spine elimination rate. Values are reported as the mean \pm SEM. $\boldsymbol{F}$, Same as $\boldsymbol{E}$ for controls with saline injection. $N=28$ and 25 fields of view across seven sessions for ketamine- and saline-injected mice. G, A histogram of the change in dendritic spine density, expressed as the fold change from day -3 to day 1 from injection. Top, saline. Bottom, ketamine. $N=58$ and 97 fields of view for ketamine- and saline-injected mice.

$328 ; p=0.02, t_{(327)}=-2.39$, paired $t$ test) and narrower (mean \pm SEM: new, $0.74 \pm 0.01 \mu \mathrm{m}$; existing, $0.83 \pm 0.02$ $\mu \mathrm{m} ; p=3 \times 10^{-5}, t_{(327)}=-4.19$, paired $t$ test). These differences in averages were reflected as differences in the cumulative distributions as well (spine length: $p=9 \times$ $10^{-6}, D_{(328,328)}=0.19$; spine width: $p=4 \times 10^{-4}$, $D_{(328,328)}=0.16$; two-sample Kolmogorov-Smirnov test; Fig. $4 B, C)$. However, when we compared pre-ketamine administration with post-ketamine administration conditions, we did not find any difference in dendritic spine morphology (spine length, new spines: $p=0.9, D_{(61,328)}=$ 0.08 ; spine length, existing spines: $p=0.09, D_{(61,328)}=$ 0.17 ; spine width, new spines: $p=0.2, D_{(61,328)}=0.15$; spine width, existing spines: $p=0.5, D_{(61,328)}=0.12$; two-sample Kolmogorov-Smirnov test). The distributions of spine protrusion length and spine head width did not suggest obvious ways to segment the data, and therefore we did not attempt to identify types (i.e., stubby, mushroom like, or filopodia like). Together, these results indicate that newly formed protrusions following systemic 
A

Fraction of new spines that persists (\%)

$$
\text { Saline }
$$
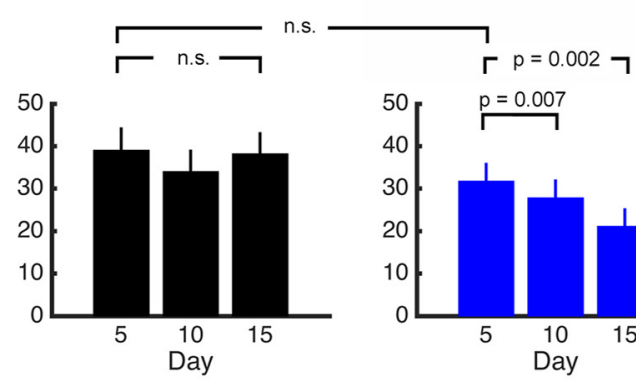

B

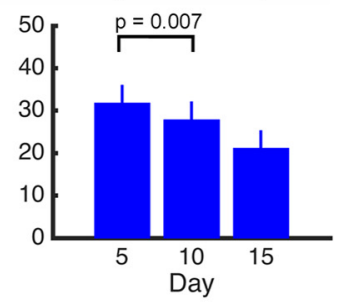

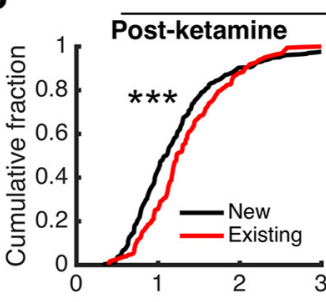

Spine protrusion length $(\mu \mathrm{m})$
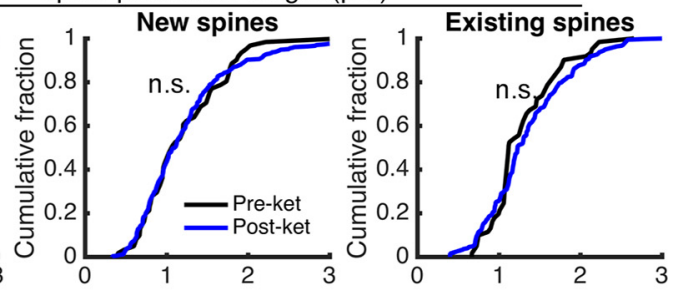

Spine head width $(\mu \mathrm{m})$

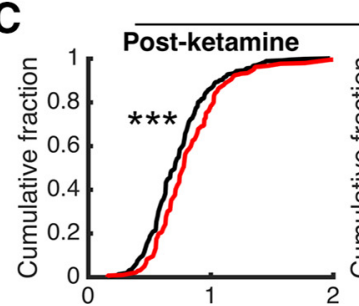

\section{New spines}

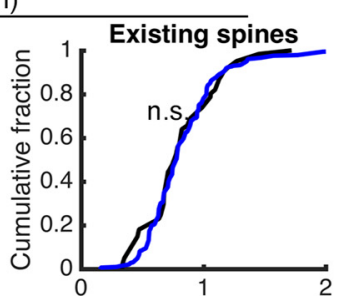

Figure 4. Newly formed protrusions following systemic ketamine administration are consistent with nascent spines. $\boldsymbol{A}$, The fraction of newly formed spines found on day 1 that could be observed again on day 5, 10, or 15 for mice injected with saline (black) or ketamine (blue). Paired $t$ test for comparisons across days in the same condition. Unpaired $t$ test for the comparison across conditions. The $p$ values are shown as is without multiple-comparison correction. Values are reported as the mean $\pm \mathrm{SEM}$. $N=28$ and 25 fields of view for ketamine- and saline-injected mice. $\boldsymbol{B}$, Distribution of spine protrusion lengths, comparing newly formed spines and existing stable spines that were on the same dendritic branch. Measurements were taken either before ketamine administration, on day -1 , or after ketamine administration, on day $1,3,5$, 10 , or $15 . * * *, p<0.001$, two-sample Kolmogorov-Smirnov test. $N=61$ new spines and 61 matched existing neighboring spines measured before ketamine administration. $N=328$ new spines and 328 matched existing neighboring spines measured after ketamine administration. $\boldsymbol{C}$, Same as $\boldsymbol{B}$ for spine head widths.

ketamine administration have similar morphological characteristics to those that occurred before systemic ketamine administration. The new spine heads are shorter and narrower, which is broadly consistent with nascent spines that precede synapse formation. Nevertheless, a fraction of these spines that formed after systemic ketamine administration becomes persistent and likely reflects new synaptic connections.

\section{Ketamine also leads to rapid retraction of distal apical tuft branches}

Unexpectedly, we also observed alterations to the distal apical tuft branches following ketamine injection in a fraction (18\%) of the fields of view (Fig. 5A). Figure $5 B$ shows the same field of view across imaging sessions where a distal branch segment was visible in a preinjection session (Fig. 5B, red arrowheads), and then disappeared on the day following systemic ketamine administration. This observation was not due to out of focus imaging, because we acquired volumetric image stacks where neuronal processes below and above the image plane were clearly visible and stable (Fig. 5B, green arrowheads). No additional alterations were observed in the subsequent days (Fig. 5C). Analysis of the longitudinal dataset revealed a mean change of $-10 \pm 3 \%$ in the total length of the imaged apical tuft branches on day 1 after ketamine injection (treatment: $p=1 \times 10^{-12}, F_{(1,236)}=56.5$; day: $p$ $=0.02, F_{(5,236)}=2.77$; interaction: $p=0.02, F_{(5,236)}=$ 2.77; two-way ANOVA; Fig. 5D). We compared fields of view with and without apical tuft branch loss and found no differences in their spine turnover rates $(p=0.2$, formation; $p=0.3$ elimination; unpaired $t$ test). We also asked whether stable and retracted dendritic branches had different widths, but did not find any difference $\left(p=0.4, t_{(131)}\right.$ $=-0.77$, unpaired $t$ test; Fig. $5 E$ ). Additional statistical tests on a per-subject basis for the three-session data confirmed a significant effect of treatment on apical tuft branch length (treatment: $p=0.003, F_{(1,16)}=12.08$; day: $p=0.7, F_{(5,16)}=0.62$; interaction: $p=0.7, F_{(5,16)}=0.62$; two-way ANOVA). These results show that systemic ketamine has a short-term effect of removing a small portion of the apical dendritic tuft branches in layer 1.

\section{Potential factors contributing to the decline of dendritic spine density prior to injection}

We observed a decline in dendritic spine density in salineinjected mice. To further investigate the potential contributing factors, we examined changes in spine density during the preinjection period, between days -3 and -1 . There were no significant differences between mice to be injected with saline versus those to be injected with ketamine $(p=1$, Wilcoxon rank-sum test; Fig. $6 A)$, or between male and female subjects $(p=0.3$, Wilcoxon ranksum test; Fig. 6B). We conjecture that stress could arise from the duration of anesthesia required for imaging, but found no systematic trend between imaging session duration and changes in spine density $\left(p=0.8 ; t_{(13)}=0.26\right.$, linear regression, excluding an outlier at -0.3 ; Fig. $6 C$ ). There was also no significant trend for the age of the animal at the time of glass window implantation $(p=0.8$; $t_{(13)}=-0.23$, linear regression, excluding outlier at -0.3 ; Fig. 6D). A potential contributor is the age of the animal at the time of imaging, where older adults tended to have larger declines in dendritic spine density $\left(p=0.16 ; t_{(13)}=\right.$ 


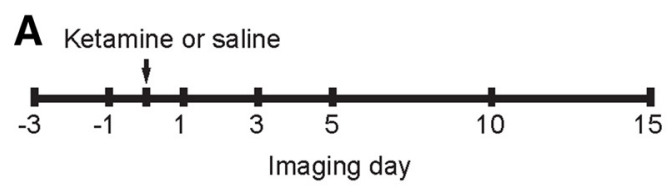

B
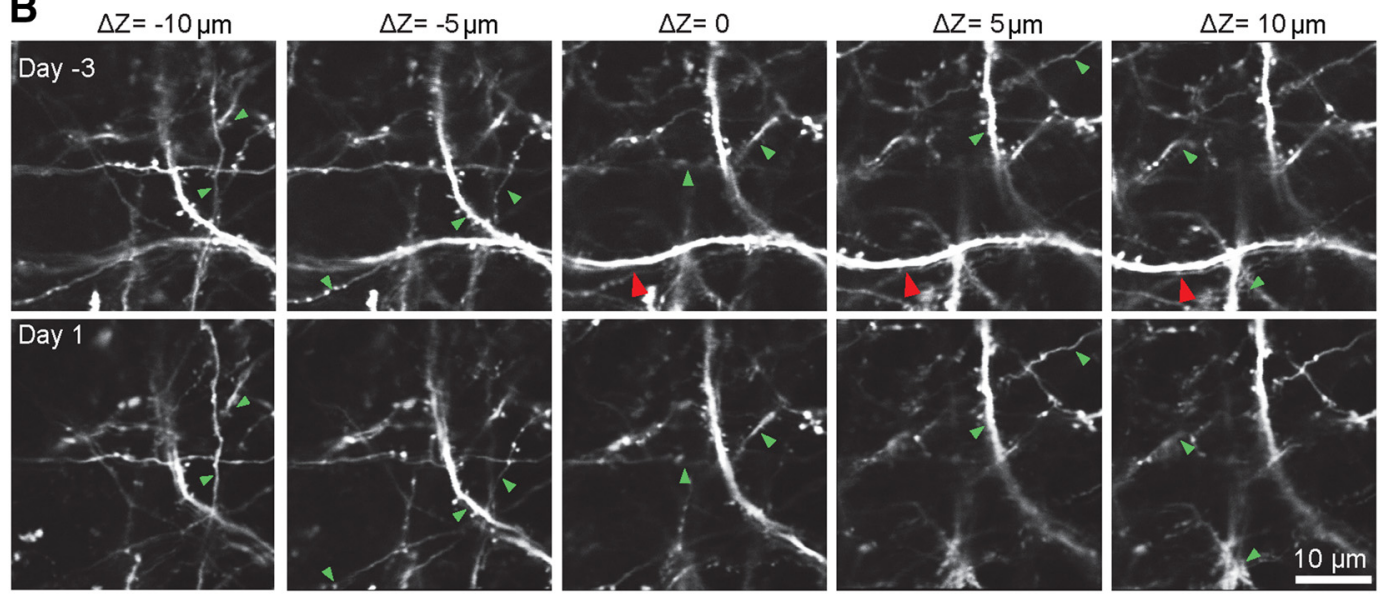

E
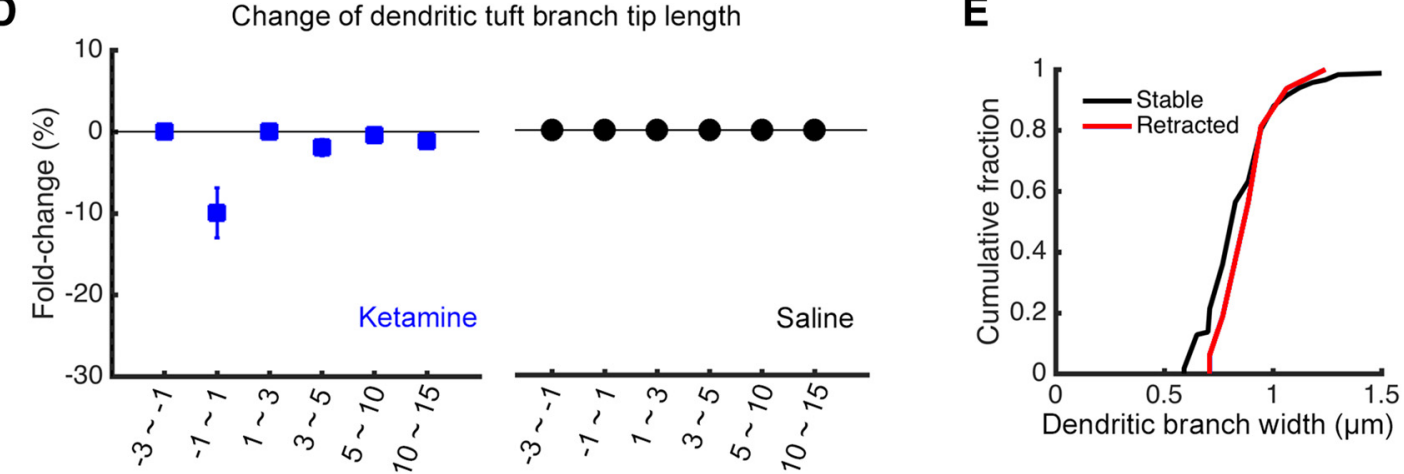

Dendritic branch width $(\mu \mathrm{m})$
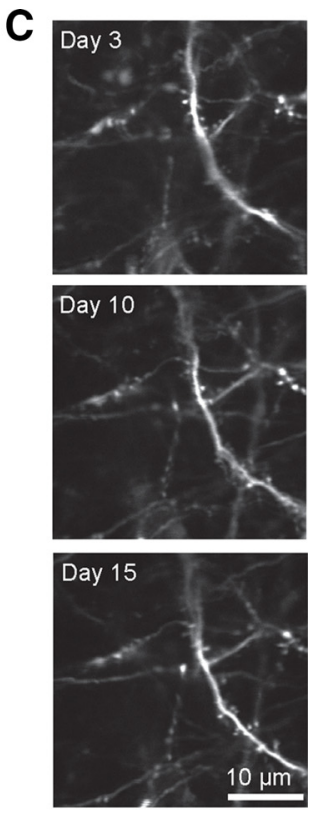

Between imaging sessions (days from injection)

Figure 5. Systemic ketamine administration associated with the retraction of distal apical tuft branches. $\boldsymbol{A}$, Time line of the experiment. Ketamine was administered at a dose of $10 \mathrm{mg} / \mathrm{kg}$ through intraperitoneal injection. $\boldsymbol{B}$, Images from multiple $z$-depths of a volumetric acquisition of dendritic architecture obtained in a Thy1-GFP-M mouse before and after ketamine administration. Note that, although most branch segments were stable (green arrowhead), a segment in the middle of the volume has retracted (red arrowhead). $\boldsymbol{C}$, Same field of view as $\boldsymbol{B}$ at days 3, 10, and 15 from ketamine administration. $\boldsymbol{D}$, Change in distal apical tuft branch length in layer 1 across days, with the fold change calculated by dividing the length of each session by that from the prior session. The mouse was injected with either ketamine (blue square) or saline vehicle (black circles). Values are reported as the mean \pm SEM. $N=28$ and 25 fields of view across seven sessions for ketamine- and saline-injected mice. $\boldsymbol{E}$, Distributions of dendritic branch widths measured on day -1 , plotted separately for those distal apical tuft branches that were stable (black) or retracted (red) on day 1. $N=117$ stable and 16 retracted dendritic segments from ketamine-injected mice.

-1.50 , linear regression, excluding an outlier at -0.3 ; Fig. $6 E)$, although this effect did not reach significance. We should note that there have been a couple of other reports (Wellman, 2001; Muñoz-Cuevas et al., 2013) of structural loss in rodent prefrontal cortex in control or vehicleinjected animals. These earlier studies along with our own data highlight the difficulty in achieving true controls in studies of frontal cortex, where the brain region is known to be sensitive to aversive life events.

\section{Discussion}

Our time-lapse results demonstrated higher dendritic spine density for up to 2 weeks after a single dose of ketamine relative to saline. This is a consequence of an elevated rate of spine formation. We also observed a loss of distal apical tuft branches that was specific to the day following ketamine injection. The short- and long-term effects on apical tuft branches and dendritic spine density would have opposite effects on the overall number of synaptic connections. By removing certain inputs immediately and adding others gradually, we suggest that ketamine may act to reorganize the types of synaptic inputs received by pyramidal neurons in the MFC. Physiological evidence hinted at this possibility; in the frontal cortex, hypocretin-sensitive synaptic inputs, likely distinct from those that mediate serotonergic signaling, originate from the thalamus. Intriguingly, although ketamine restores the 

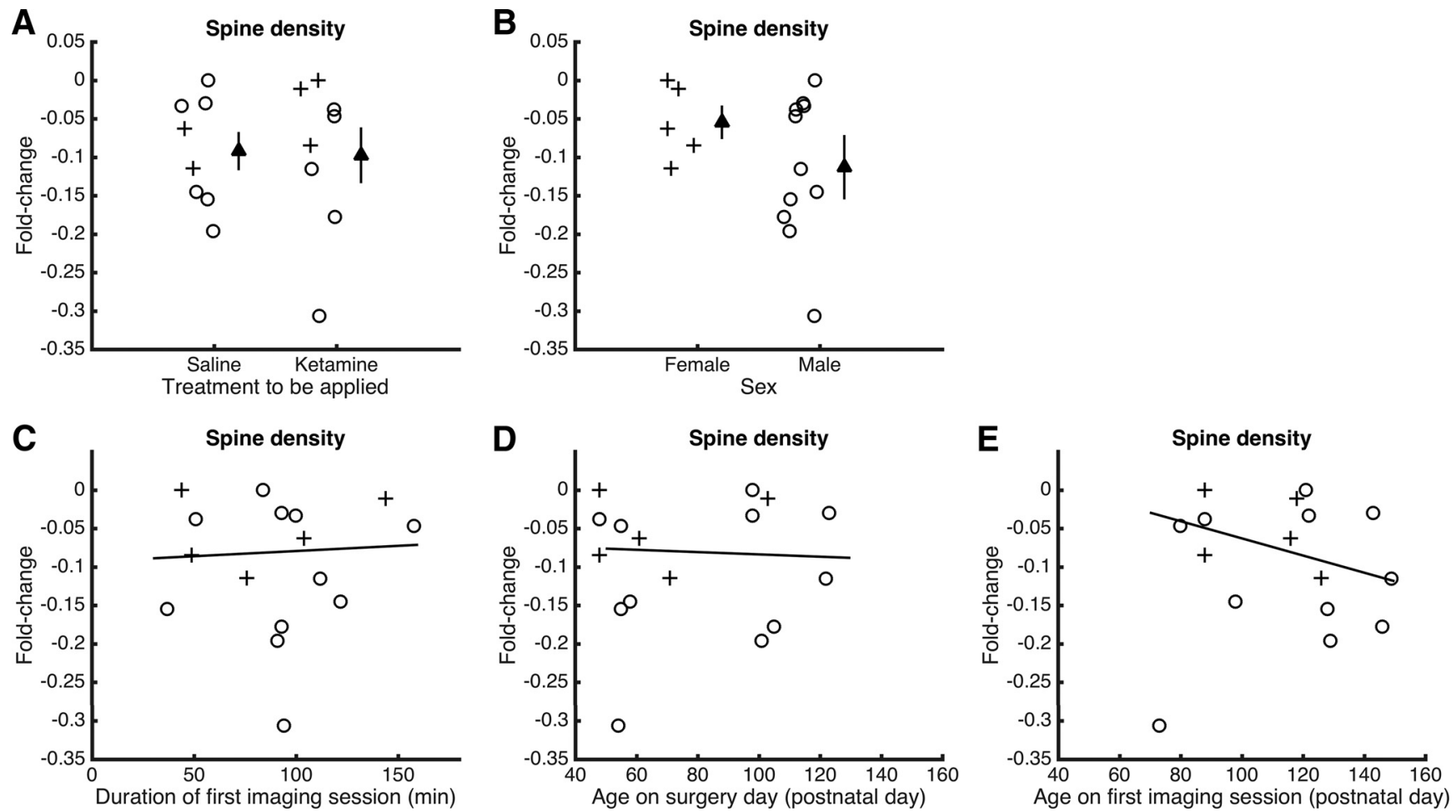

Figure 6. Potential factors contributing to the decline of dendritic spine density prior to injection. $\boldsymbol{A}$, Fold change in dendritic spine density from day -3 to day -1 (preinjection) for mice to be injected with saline or ketamine. Circle, male. Cross, female. Filled triangle, mean \pm SEM. $\boldsymbol{B}$, Same as $\boldsymbol{A}$ for female vs male mice. $\boldsymbol{C}$, Fold change in dendritic spine density from day -3 to day -1 (preinjection) plotted as a function of the duration of the imaging session on day -3 . Circle, male. Cross, female. Line, linear fit excluding the outlier at -0.3 . $\boldsymbol{D}$, Same as $\boldsymbol{C}$ for age at the time of surgery. $\boldsymbol{E}$, Same as $\boldsymbol{C}$ for age at the time of the first imaging session.

magnitude of these synaptic currents in stressed rats, they appear to reach different levels relative to baseline ( $\mathrm{Li}$ et al., 2011). Further experiments are needed to confirm the identities of the added and lost synaptic connections following systemic ketamine administration.

Our study builds on previous studies (Li et al., 2010, 2011) of ketamine in naive rats and chronic stress models, which found an increase in dendritic spine density in the distal and proximal tufts of layer 5 pyramidal neurons. These studies examined structural changes in the anterior cingulate and prelimbic regions by filling cells in brain slices prepared $24 \mathrm{~h}$ after treatment. Here, investigating effects in vivo, we found a relative increase in spine density in the MFC, which is more dorsally located but still part of the rodent medial prefrontal cortical network (Van De Werd et al., 2010; Vogt and Paxinos, 2014). We should emphasize that the observed relative increase is a result of dendritic spine density remaining mostly stable for ketamine, but declining for saline-injected mice. The decline of spine density in the saline group suggests that mice might have been stressed inadvertently in our experiments, potentially as a function of age at the time of imaging. Interestingly, other studies have observed an increase in dendritic spine density following a single dose of another rapid-acting antidepressant, scopolamine (Voleti et al., 2013), and reversal of stress-induced atrophy by long-term administration of fluoxetine (Bessa et al., 2009). Therefore, our results and studies in the field (Bessa et al.,
2009; Li et al., 2010, 2011; Voleti et al., 2013) support a structural basis for antidepressant actions that may generalize beyond specific frontal cortical regions or pharmacological agents.

A novel finding is that the higher dendritic spine density after systemic ketamine administration is due to an elevated spine formation rate, but not to changes in the spine elimination rate. This increase in spine formation rate was largest on the day after systemic ketamine administration. For the later imaging sessions, the spine formation rate remained above the baseline, preinjection levels. This time course of elevated spine formation rate may be compared with the time course of the antidepressant effects of systemic ketamine. In rats, depressive-like behaviors, as assayed by forced swim and sucrose preference tests, were reduced 1 week after the injection of ketamine (Autry et al., 2011; Li et al., 2011). In patients with major depressive disorder, the duration of the antidepressant effects of ketamine varies from $3 \mathrm{~d}$ to 2 weeks (Ibrahim et al., 2012). Therefore, the long-term effect on dendritic spine turnover may relate to the sustained antidepressant effects observed in rodents and humans. Furthermore, the observation of changes in the dynamics of the spine formation rate, but not in other structural plasticity parameters, suggests that antidepressant effects may rely on molecular pathways that promote synaptogenesis, rather than those related to spine growth or pruning. 
Several factors may influence the rates of ketamineinduced structural remodeling. Sex is a contributing variable because estrogen is known to affect structural plasticity (Srivastava et al., 2008). In this study, sex differences were not tested explicitly, owing to the limited sample size. Two lines of evidence suggest that pooling the data from males and females should not affect the conclusions of this study. First, we repeated the analysis using data from the five ketamine-injected males only, and found similar trends for ketamine-induced changes, including a relative increase in dendritic spine density and an elevated spine formation rate, but no change in the spine elimination rate. Second, two recent studies (Carrier and Kabbaj, 2013; Franceschelli et al., 2015) reported that although female rats are more sensitive to the antidepressant-like effects of ketamine at low dose, behavioral outcomes are similar between males and females at higher doses. Here, we used a dose $(10 \mathrm{mg} / \mathrm{kg})$ at which these studies found comparable behavioral effects for the sexes. Another potential variable is the surgical method. One report (Xu et al., 2007) argued that open-skull craniotomy can alter dendritic spine turnover rates, although another study (Holtmaat et al., 2009) found negligible differences across surgical preparations. The same procedures were applied to the ketamine and saline groups in our study; therefore, the influence of surgical methods on the across-group differences should be minimal. Furthermore, ketamine is often used with xylazine as an anesthetic. There is evidence that an anesthetic dose of ketamine has transient effects on the dynamics of dendritic filopodia but no effect on dendritic spines in 1-month-old mice (Yang et al., 2011). It is unclear how this prior result compares with the current findings, because we used a subanesthetic dose.

A surprising observation was the retraction of distal apical tuft branches, specific to the day after systemic ketamine administration. We emphasize that the imaged branch segments reside in the superficial layers of the cortex, therefore representing the distal portion and only a tiny fraction of the entire dendritic tree of a neuron. The loss of apical tuft branch tips may be due to the retraction of dendritic branches or the death of the neurons from which these dendrites arise, possibilities that could not be distinguished from our data. Nevertheless, our result was unexpected because, although some cortical cell types such as GABAergic interneurons can undergo branch tip reorganization under certain conditions (Chen et al., 2011), the dendritic branches of pyramidal neurons are thought to be stable in the neocortex of adult mice (Grutzendler et al., 2002). Studies have shown that structural plasticity in MFC is important for cognitive behaviors such as consolidation of contextual memory (Vetere et al., 2011) and adaptive decision-making (Liston et al., 2006; Dias-Ferreira et al., 2009). Therefore, the loss of dendritic materials may contribute to cognitive impairments, which are known to affect long-term ketamine users (Morgan et al., 2009). At higher dosages, repeated ketamine use has been associated with a reduced volume of hippocampus and frontal lobe in humans (Liao et al., 2011) and rodents (Kassem et al., 2013; Schobel et al., 2013). One correlated functional imaging study (Kassem et al., 2013) showed that such gray matter reduction is primarily due to a loss of dendrites and their synapses. There are ongoing efforts in the field to develop compounds with ketaminelike antidepressant actions but without the psychotomimetic effects, and it would be interesting to test whether those drugs may promote structural plasticity but spare dendritic material loss.

The short- and long-term effects of distal tuft branch loss and elevated spine formation rate have opposing effects on the total number of dendritic spines in the MFC. Long-range inputs into the superficial layers of rodent MFC come from multiple sources, including mediodorsal and midline thalamic nuclei, basolateral amygdala, and other prefrontal cortical areas (Hoover and Vertes, 2007; Oh et al., 2014). Specific types of prefrontal cortical inputs and outputs may be more plastic and susceptible to stress or ketamine (Shansky et al., 2009; Liu et al., 2015). Therefore, approaches that can alter prefrontal cortical circuitry with pathway specificity may be effective treatment options for mood disorders and merit further study.

\section{References}

Autry AE, Adachi M, Nosyreva E, Na ES, Los MF, Cheng P-F, Kavalali ET, Monteggia LM (2011) NMDA receptor blockade at rest triggers rapid behavioural antidepressant responses. Nature 475:91-95. CrossRef Medline

Berman RM, Cappiello A, Anand A, Oren DA, Heninger GR, Charney DS, Krystal JH (2000) Antidepressant effects of ketamine in depressed patients. Biol Psychiatry 47:351-354. Medline

Bessa JM, Ferreira D, Melo I, Marques F, Cerqueira JJ, Palha JA, Almeida OFX, Sousa N (2009) The mood-improving actions of antidepressants do not depend on neurogenesis but are associated with neuronal remodeling. Mol Psychiatry 14:764-73-739. CrossRef Medline

Carrier N, Kabbaj M (2013) Sex differences in the antidepressant-like effects of ketamine. Neuropharmacology 70:27-34. CrossRef Medline

Cerqueira JJ, Taipa R, Uylings HBM, Almeida OFX, Sousa N (2007) Specific configuration of dendritic degeneration in pyramidal neurons of the medial prefrontal cortex induced by differing corticosteroid regimens. Cereb Cortex 17:1998-2006. CrossRef

Chen JL, Lin WC, Cha JW, So PT, Kubota Y, Nedivi E (2011) Structural basis for the role of inhibition in facilitating adult brain plasticity. Nat Neurosci 14:587-594. CrossRef Medline

Christoffel DJ, Golden SA, Russo SJ (2011) Structural and synaptic plasticity in stress-related disorders. Rev Neurosci 22:535-549. CrossRef Medline

Cook SC, Wellman CL (2004) Chronic stress alters dendritic morphology in rat medial prefrontal cortex. J Neurobiol 60:236-248. CrossRef Medline

Dias-Ferreira E, Sousa JC, Melo I, Morgado P, Mesquita AR, Cerqueira JJ, Costa RM, Sousa N (2009) Chronic stress causes frontostriatal reorganization and affects decision-making. Science 325:621-625. CrossRef Medline

Donahue RJ, Muschamp JW, Russo SJ, Nestler EJ, Carlezon WA (2014) Effects of striatal $\Delta$ FosB overexpression and ketamine on social defeat stress-induced anhedonia in mice. Biol Psychiatry 76:550-558. CrossRef Medline

Drevets WC, Price JL, Simpson JR, Todd RD, Reich T, Vannier M, Raichle ME (1997) Subgenual prefrontal cortex abnormalities in mood disorders. Nature 386:824-827. CrossRef Medline

Duman RS, Aghajanian GK (2012) Synaptic dysfunction in depression: potential therapeutic targets. Science 338:68-72. CrossRef Medline 
Duncan GE, Miyamoto S, Leipzig JN, Lieberman JA (1999) Comparison of brain metabolic activity patterns induced by ketamine, MK-801 and amphetamine in rats: support for NMDA receptor involvement in responses to subanesthetic dose of ketamine. Brain Res 843:171-183. Medline

Feng G, Mellor RH, Bernstein M, Keller-Peck C, Nguyen QT, Wallace M, Nerbonne JM, Lichtman JW, Sanes JR (2000) Imaging neuronal subsets in transgenic mice expressing multiple spectral variants of GFP. Neuron 28:41-51. Medline

Franceschelli A, Sens J, Herchick S, Thelen C, Pitychoutis PM (2015) Sex differences in the rapid and the sustained antidepressant-like effects of ketamine in stress-naïve and "depressed" mice exposed to chronic mild stress. Neuroscience 290:49-60. CrossRef Medline

Fu M, Yu X, Lu J, Zuo Y (2012) Repetitive motor learning induces coordinated formation of clustered dendritic spines in vivo. Nature 483:92-95. CrossRef Medline

Fuchikami M, Thomas A, Liu R, Wohleb ES, Land BB, DiLeone RJ, Aghajanian GK, Duman RS (2015) Optogenetic stimulation of infralimbic PFC reproduces ketamine's rapid and sustained antidepressant actions. Proc Natl Acad Sci U S A 112:8106-8111. CrossRef Medline

Grutzendler J, Kasthuri N, Gan W-B (2002) Long-term dendritic spine stability in the adult cortex. Nature 420:812-816. CrossRef Medline

Holtmaat A, Bonhoeffer T, Chow DK, Chuckowree J, De Paola V, Hofer SB, Hübener M, Keck T, Knott G, Lee W-CA, Mostany R, Mrsic-Flogel TD, Nedivi E, Portera-Cailliau C, Svoboda K, Trachtenberg JT, Wilbrecht L (2009) Long-term, high-resolution imaging in the mouse neocortex through a chronic cranial window. Nat Protoc 4:1128-1144. CrossRef

Hoover WB, Vertes RP (2007) Anatomical analysis of afferent projections to the medial prefrontal cortex in the rat. Brain Struct Funct 212:149-179. CrossRef Medline

Ibrahim L, DiazGranados N, Franco-Chaves J, Brutsche N, Henter ID, Kronstein P, Moaddel R, Wainer I, Luckenbaugh DA, Manji HK, Zarate CA (2012) Course of improvement in depressive symptoms to a single intravenous infusion of ketamine vs add-on riluzole: results from a 4-week, double-blind, placebo-controlled study. Neuropsychopharmacology 37:1526-1533. CrossRef Medline

Ito H, Nagano M, Suzuki H, Murakoshi T (2010) Chronic stress enhances synaptic plasticity due to disinhibition in the anterior cingulate cortex and induces hyper-locomotion in mice. Neuropharmacology 58:746-757. CrossRef Medline

Kang HJ, Voleti B, Hajszan T, Rajkowska G, Stockmeier CA, Licznerski P, Lepack A, Majik MS, Jeong LS, Banasr M, Son H, Duman RS (2012) Decreased expression of synapse-related genes and loss of synapses in major depressive disorder. Nat Med 18:1413-1417. CrossRef Medline

Kasai H, Matsuzaki M, Noguchi J, Yasumatsu N, Nakahara H (2003) Structure-stability-function relationships of dendritic spines. Trends Neurosci 26:360-368. CrossRef Medline

Kassem MS, Lagopoulos J, Stait-Gardner T, Price WS, Chohan TW, Arnold JC, Hatton SN, Bennett MR (2013) Stress-induced grey matter loss determined by MRI is primarily due to loss of dendrites and their synapses. Mol Neurobiol 47:645-661. CrossRef Medline

Kim Y, Perova Z, Mirrione MM, Pradhan K, Henn FA, Shea S, Osten P, Li B (2016) Whole-brain mapping of neuronal activity in the learned helplessness model of depression. Front Neural Circuits 10:3. CrossRef Medline

Knott GW, Holtmaat A, Wilbrecht L, Welker E, Svoboda K (2006) Spine growth precedes synapse formation in the adult neocortex in vivo. Nat Neurosci 9:1117-1124. CrossRef Medline

Lai CSW, Franke TF, Gan W-B (2013) Opposite effects of fear conditioning and extinction on dendritic spine remodelling. Nature 482:87-91.

Li N, Lee B, Liu R-J, Banasr M, Dwyer JM, Iwata M, Li X-Y, Aghajanian G, Duman RS (2010) mTOR-dependent synapse formation underlies the rapid antidepressant effects of NMDA antagonists. Science 329:959-964. CrossRef Medline
Li N, Liu R-J, Dwyer JM, Banasr M, Lee B, Son H, Li X-Y, Aghajanian G, Duman RS (2011) Glutamate N-methyl-D-aspartate receptor antagonists rapidly reverse behavioral and synaptic deficits caused by chronic stress exposure. Biol Psychiatry 69:754-761. CrossRef Medline

Liao Y, Tang J, Corlett PR, Wang X, Yang M, Chen H, Liu T, Chen X, Hao W, Fletcher PC (2011) Reduced dorsal prefrontal gray matter after chronic ketamine use. Biol Psychiatry 69:42-48. CrossRef Medline

Liston C, Gan W-B (2011) Glucocorticoids are critical regulators of dendritic spine development and plasticity in vivo. Proc Natl Acad Sci U S A 108:16074-16079. CrossRef Medline

Liston C, Miller MM, Goldwater DS, Radley JJ, Rocher AB, Hof PR, Morrison JH, McEwen BS (2006) Stress-induced alterations in prefrontal cortical dendritic morphology predict selective impairments in perceptual attentional set-shifting. J Neurosci 26:78707874. CrossRef Medline

Liu R-J, Fuchikami M, Dwyer JM, Lepack AE, Duman RS, Aghajanian GK (2013) GSK-3 inhibition potentiates the synaptogenic and antidepressant-like effects of subthreshold doses of ketamine. Neuropsychopharmacology 38:2268-2277. CrossRef Medline

Liu R-J, Ota KT, Dutheil S, Duman RS, Aghajanian GK (2015) Ketamine strengthens CRF-activated amygdala inputs to basal dendrites in mPFC layer V pyramidal cells in the prelimbic but not infralimbic subregion, a key suppressor of stress responses. Neuropsychopharmacology 40:2066-2075. CrossRef

Miyamoto S, Leipzig JN, Lieberman JA, Duncan GE (2000) Effects of ketamine, MK-801, and amphetamine on regional brain 2-deoxyglucose uptake in freely moving mice. Neuropsychopharmacology 22:400-412. CrossRef Medline

Morgan CJA, Muetzelfeldt L, Curran HV (2009) Ketamine use, cognition and psychological wellbeing: a comparison of frequent, infrequent and ex-users with polydrug and non-using controls. Addiction 104:77-87. CrossRef Medline

Muñoz-Cuevas FJ, Athilingam J, Piscopo D, Wilbrecht L (2013) Cocaine-induced structural plasticity in frontal cortex correlates with conditioned place preference. Nat Neurosci 16:1367-1369. CrossRef Medline

Murray CJ, Atkinson C, Bhalla K, Birbeck G, Burstein R, Chou D, Dellavalle R, Danaei G, Ezzati M, Fahimi A, Flaxman D, Foreman, Gabriel S, Gakidou E, Kassebaum N, Khatibzadeh S, Lim S, Lipshultz SE, London S, Lopez, et al (2013) The state of US health, 1990-2010: burden of diseases, injuries, and risk factors. JAMA 310:591-608. CrossRef

Oh SW, Harris JA, Ng L, Winslow B, Cain N, Mihalas S, Wang Q, Lau C, Kuan L, Henry AM, Mortrud MT, Ouellette B, Nguyen TN, Sorensen SA, Slaughterbeck CR, Wakeman W, Li Y, Feng D, Ho A, Nicholas E, et al. (2014) A mesoscale connectome of the mouse brain. Nature 508:207-214. CrossRef Medline

Pologruto TA, Sabatini BL, Svoboda K (2003) Scanlmage: flexible software for operating laser scanning microscopes. Biomed Eng Online 2:13. CrossRef Medline

Radley JJ, Rocher AB, Miller M, Janssen WGM, Liston C, Hof PR, McEwen BS, Morrison JH (2006) Repeated stress induces dendritic spine loss in the rat medial prefrontal cortex. Cereb Cortex 16:313-320. CrossRef

Radley JJ, Sisti HM, Hao J, Rocher AB, McCall T, Hof PR, McEwen BS, Morrison JH (2004) Chronic behavioral stress induces apical dendritic reorganization in pyramidal neurons of the medial prefrontal cortex. Neuroscience 125:1-6. CrossRef Medline

Ruddy RM, Chen Y, Milenkovic M, Ramsey AJ (2015) Differential effects of NMDA receptor antagonism on spine density. Synapse 69:52-56. CrossRef Medline

Sanacora G, Schatzberg AF (2015) Ketamine: promising path or false prophecy in the development of novel therapeutics for mood disorders? Neuropsychopharmacology 40:259-267. CrossRef

Schneider CA, Rasband WS, Eliceiri KW (2012) NIH Image to ImageJ: 25 years of image analysis. Nat Methods 9:671-675. Medline

Schobel SA, Chaudhury NH, Khan UA, Paniagua B, Styner MA, Asllani I, Inbar BP, Corcoran CM, Lieberman JA, Moore H, Small 
SA (2013) Imaging patients with psychosis and a mouse model establishes a spreading pattern of hippocampal dysfunction and implicates glutamate as a driver. Neuron 78:81-93. CrossRef

Shansky RM, Hamo C, Hof PR, McEwen BS, Morrison JH (2009) Stress-induced dendritic remodeling in the prefrontal cortex is circuit specific. Cereb Cortex 19:2479-2484. CrossRef Medline

Srivastava DP, Woolfrey KM, Woolfrey K, Jones KA, Shum CY, Lash LL, Swanson GT, Penzes P (2008) Rapid enhancement of two-step wiring plasticity by estrogen and NMDA receptor activity. Proc Natl Acad Sci U S A 105:14650-14655. CrossRef Medline

Thévenaz P, Ruttimann UE, Unser M (1998) A pyramid approach to subpixel registration based on intensity. IEEE Trans Image Process 7:27-41. CrossRef Medline

Trachtenberg JT, Chen BE, Knott GW, Feng G, Sanes JR, Welker E, Svoboda K (2002) Long-term in vivo imaging of experiencedependent synaptic plasticity in adult cortex. Nature 420:788-794. CrossRef Medline

Van De Werd HJ, Rajkowska G, Evers P, Uylings HB (2010) Cytoarchitectonic and chemoarchitectonic characterization of the prefrontal cortical areas in the mouse. Brain Struct Funct 214:339353. CrossRef Medline
Vetere G, Restivo L, Cole CJ, Ross PJ, Ammassari-Teule M, Josselyn SA, Frankland PW (2011) Spine growth in the anterior cingulate cortex is necessary for the consolidation of contextual fear memory. Proc Natl Acad Sci U S A 108:8456-8460. CrossRef Medline

Vogt BA, Paxinos G (2014) Cytoarchitecture of mouse and rat cingulate cortex with human homologies. Brain Struct Funct 219:185192. CrossRef Medline

Voleti B, Navarria A, Liu R-J, Banasr M, Li N, Terwilliger R, Sanacora G, Eid T, Aghajanian G, Duman RS (2013) Scopolamine rapidly increases mammalian target of rapamycin complex 1 signaling, synaptogenesis, and antidepressant behavioral responses. Biol Psychiatry 74:742-749.

Wellman CL (2001) Dendritic reorganization in pyramidal neurons in medial prefrontal cortex after chronic corticosterone administration. J Neurobiol 49:245-253. Medline

Xu H-T, Pan F, Yang G, Gan W-B (2007) Choice of cranial window type for in vivo imaging affects dendritic spine turnover in the cortex. Nat Neurosci 10:549-551. CrossRef Medline

Yang G, Chang PC, Bekker A, Blanck TJJ, Gan W-B (2011) Transient effects of anesthetics on dendritic spines and filopodia in the living mouse cortex. Anesthesiology 115:718-726. CrossRef Medline 